\title{
Commentary: Double-outlet right ventricle: Complex solutions for a complex anomaly
}

\author{
Harold M. Burkhart, MD, ${ }^{a}$ Jess L. Thompson, MD, ${ }^{a}$ and Arshid Mir, MD
}

\footnotetext{
From the ${ }^{\mathrm{a} D i v i s i o n}$ of Cardiovascular and Thoracic Surgery and ${ }^{\mathrm{b}}$ Section of Pediatric Cardiology, University of Oklahoma Health Sciences Center, Oklahoma City, Okla.

Disclosures: Authors have nothing to disclose with regard to commercial support.

Received for publication Aug 22, 2019; revisions received Aug 22, 2019; accepted for publication Aug 26, 2019; available ahead of print Oct 9, 2019.

Address for reprints: Harold M. Burkhart, MD, Division of Cardiovascular and Thoracic Surgery, University of Oklahoma Health Sciences Center, P.O. Box 26901, WP-2230, Oklahoma City, OK 73105 (E-mail: Harold-burkhart@ouhsc.edu).

J Thorac Cardiovasc Surg 2020;159:266-7

$0022-5223 / \$ 36.00$

Copyright $(2019$ by The American Association for Thoracic Surgery

https://doi.org/10.1016/j.jtcvs.2019.08.084
}

More than 5 decades ago, Kirklin and colleagues ${ }^{1}$ reported the first case of surgical repair in a child with double-outlet right ventricle (DORV), concordant atrioventricular connections, and a subaortic interventricular defect in Journal. Over the ensuing years, an immense amount of thought has gone into finding surgical solutions to this complicated defect. DORV is a heterogeneous group of congenital heart disease that requires an individualized surgical approach based on a precise understanding of the often-complex cardiovascular anatomy. Of concern, when discussing surgical approaches to DORV, is that this diagnosis constitutes a broad spectrum of phenotypes, making it difficult to categorize and subcategorize these patients for analysis. Ebadi and colleagues ${ }^{2}$ recently reported a marked degree of variability in infundibular morphology seen in 100 DORV anatomic specimens, with only a quarter having bilateral infundibula and most having some degree of semilunar-to-atrioventricular valvar fibrous continuity. A successful biventricular (BiV) repair involves an unobstructed interventricular baffle to the aortic valve, or the nearest semilunar valve with an arterial switch operation, without compromising the right ventricular inlet dimension, tricuspid valve function, right and left ventricular outflow tracts, and ventricular volumes. Not surprisingly, a $\mathrm{BiV}$ repair is not always possible in the complex patients, necessitating a single-ventricle palliation (SVP) route.

In this issue of the Journal, Oladunjoye and colleagues ${ }^{4}$ present data from a retrospective analysis of all patients who underwent a BiV repair for DORV at Boston Children's Hospital between January 2000 and December 2017. The patients were divided into 2 groups: those who had primary $\mathrm{BiV}$ repair and those who underwent a staged $\mathrm{BiV}$ repair using a series of operations. Interestingly, the primary BiV group included patients with a history of pulmonary artery banding. The staged $\mathrm{BiV}$ group was generally a more complex group anatomically, with many having been considered for SVP at one time. Surgical results

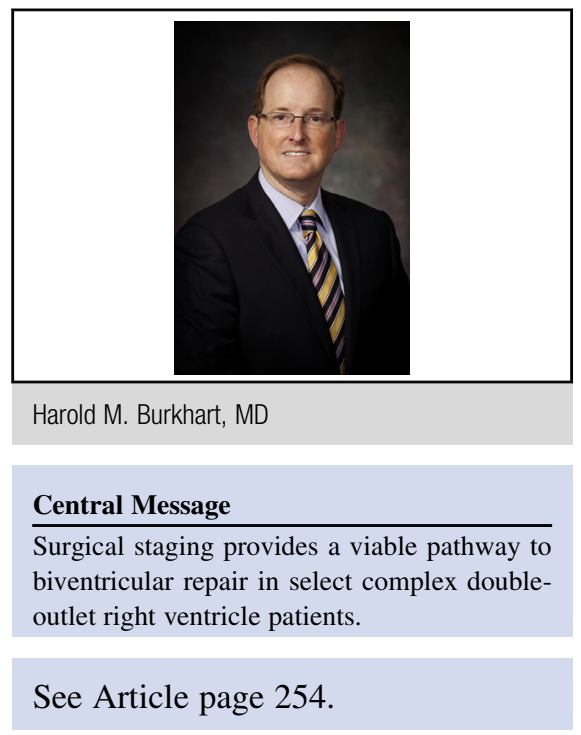

were excellent, with 5-year survival being $89 \%$ and 5-year freedom from left ventricular outflow tract obstruction reported to be $84 \%$. The authors provide their rational for using a staged approach, including the complexity of intracardiac anatomy, age and size of the patient, function of the ventricles and atrioventricular valves, as well as the need for a long left ventricle to aorta pathway in an infant. Their ability to obtain a successful $\mathrm{BiV}$ repair in patients with marginal anatomy, some of whom were initially deemed destined for SVP, through surgical staging manipulations is noteworthy and a definite strength of the manuscript.

There are a few limitations to the study. The never-ending question in the surgical management of DORV is when is a patient's anatomy too complex for a BiV repair. It would be valuable to know how many patients with DORV during the same time period were treated with an SVP pathway. Furthermore, how many patients started out as a planned $\mathrm{BiV}$ repair but had to be switched over to the single-ventricle route? Delineating their criteria for the SVP option in DORV would have strengthened the manuscript. In addition, a more detailed algorithm outlining the surgical stages taken to arrive at a BiV repair would have been appreciated. Given the institution's broad experience with ventricular recruitment, insight into the indications for and timing of cavopulmonary shunts and partial interventricular defect closure, for example, would have been valuable to the readership. 
In summary, constructing a nonobstructive interventricular baffle, with or without an arterial switch, while maintaining appropriate ventricular volumes and outflow tracts, as well as competent atrioventricular valves, remains the ultimate goal in achieving BiV repair in DORV. A staged approach in the more complex patients seems to provide a viable pathway to reaching that goal. These surgical techniques, as well as enhanced imaging such as 3 -dimensional cardiac printing, ${ }^{5}$ will undoubtedly aid the surgeon in defining the appropriate complex treatment solutions to these complex anomalies.

\section{References}

1. Kirklin JW, Harp RA, McGoon DC. Surgical treatment of origin of both vessels from right ventricle, including cases of pulmonary stenosis. J Thorac Cardiovasc Surg. 1964;48:1026-36

2. Ebadi A, Spicer DE, Backer CL, Fricker FJ, Anderson RH. Double-outlet right ventricle revisited. J Thorac Cardiovasc Surg. 2017;154:598-604.

3. Brown JW, Ruzmetov M, Okada Y, Vijay P, Turrentine MW. Surgical results in patients with double outlet right ventricle: a 20-year experience. Ann Thorac Surg. 2001;72:1630-5.

4. Oladunjoye O, Piekarski B, Baird C, Banka P, Marx G, del Nido PJ, et al. Repair of double outlet right ventricle: midterm outcomes. J Thorac Cardiovasc Surg. 2020; 159:254-64.

5. Yoo SJ, van Arsdell GS. 3D printing in surgical management of double outlet right ventricle. Front Pediatr. 2018;5:289. 